\title{
Effect of Workplace Factors in Professional Teacher Development on the Implementation of Small Class Teaching
}

\author{
Jacky Pow $^{1}$, Marina Wong ${ }^{1}$ \\ ${ }^{1}$ Department of Education Studies, Hong Kong Baptist University, China \\ Correspondence: Jacky Pow, Department of Education Studies, Hong Kong Baptist University, China.
}

Received: May 26, 2017

Accepted: July 6, 2017

Online Published: July 12, 2017

doi:10.11114/jets.v5i8.2441

URL: https://doi.org/10.11114/jets.v5i8.2441

\begin{abstract}
It is commonly believed that small class teaching can greatly enhance student learning because the individual needs of each student can be better addressed, the students can learn more through more innovative and flexible teaching methods and the students have more time to interact with each other and to gain feedback from their teachers. Although studies have shown that students benefit from small class teaching, they have failed to identify the benefits as the natural consequences of a simple reduction in class size. As increasing numbers of researchers argue that professional development in small class teaching is more important than a simple reduction in class size, it is timely to determine the factors that affect teachers' participation in small class teaching professional development programmes and their use of small class teaching after participation in these programmes. This study explored teachers' concerns about or obstacles to applying their knowledge from professional development programmes to their teaching. Teachers who had participated in a government-funded professional development programme were invited to complete an end-of-programme questionnaire, and 160 valid questionnaires were collected. The initial findings indicate that workplace factors were the most common factors in the implementation of small class teaching.
\end{abstract}

Keywords: teachers' professional development, small class teaching, workplace factors

\section{Introduction}

The changing demographic structure in Hong Kong in the past decade has been a challenge not only to Hong Kong's economy but also to its education system. In 2007, the Government of Hong Kong Special Administrative Region (HKSAR), in response to falling birth rates and declining school enrolment, announced the phase-by-phase implementation of small class teaching in government and aided primary schools with the aim of full implementation (i.e., from Primary 1 to Primary 6) by the 2013/14 school year (Wong \& Pow, 2012). The class size was reduced to 25, partly to avoid the need to close more schools in some local districts and partly to increase the quality of teaching and learning.

When the initiative was launched, it was believed that small class teaching would greatly enhance student learning. For example, the individual needs of the students could be better addressed (Graue, Hatch, Rao, \& Oen, 2007), students would learn more through more innovative and flexible teaching methods (Çakmak, 2009) and students would have more time to interact with each other and to gain feedback from their teachers (Finn, Pannozzo, \& Achilles, 2003). Unfortunately, gaining access to these benefits has not been as easy or simple as initially thought. Problems arise when teachers who work with small classes are unable to take advantage of the class size and stick to their old practices (Harfitt, 2012). Therefore, the intended benefits might be regarded only as 'motherhood statements' with no strong evidence to support them due to the ambiguity and inconsistency of class size research (Pedder, 2006). Although empirical studies have shown that students benefit from small class teaching, they have failed to show that the benefits are a natural consequence of a simple reduction in class size. As increasing numbers of researchers argue that professional development in small class teaching is more important than a simple reduction in class size (Finn et al., 2003, Blatchford et al., 2003, Graue et al., 2007), it is timely to determine whether teachers can actually apply what they have learnt in professional development courses in a small class environment.

This study explored factors that affect teachers' participation in small class teaching professional development programmes and their concerns about or obstacles to applying what they have learnt in these programmes in their school setting. The findings form a useful reference for school administrators who wish to access the real benefits of small class teaching, develop a holistic strategy in professional development and determine a wiser method of allocating school resources. 


\section{Teachers' Professional Development}

\subsection{Factors of Teachers' Participation in CPD}

There is little doubt that continuing professional development (CPD) is important in every teacher's career growth (Edmonds, 2007). In Hong Kong, the Government uses a 'soft' approach that allows schools to decide on policies about their own professional development strategies and allows teachers to have professional autonomy. The Committee on Professional Development of Teachers and Principals (formerly the Advisory Committee on Teacher Education and Qualifications, ACTEQ), a non-statutory body under the purview of the Education Bureau, recommended (1) a target of about 150 CPD hours over 3 years; (2) that the modes and content of the CPD activities be defined by schools; and (3) that schools exercise professional autonomy in monitoring the implementation of teachers' CPD (ACTEQ 2009, p. 23). Although teachers might have the flexibility to choose their CPD activities, what factors affect their participation in CPD?

Explanations of teachers' participation in professional development activities are usually linked to the Teacher Career Cycle Model (Fessler, 1992), which can be broken down into roughly eight stages of teachers' professional development: (1) pre-service, (2) induction, (3) competency building, (4) enthusiasm and growth, (5) stability, (6) frustration, (7) career wind-down and (8) career exit. Each stage can be used to explain the extent of a teacher's participation in professional development, although it is not certain that every teacher will go through every stage (Fessler \& Christensen, 1992). This model suggests that the motivation behind a teacher's engagement in professional growth changes as he or she passes through the various stages of development. In other words, teachers are more likely to participate in CPD in the first stage because these are their growing and golden stages of their career. When they reach the stability stage, they may be more passive and indifferent to CPD activities. As they pass through the last three stages, their motivation to participate in any CPD activity declines even further. This model is based on the perspectives of teachers and is therefore subjective in nature. As a result, this model alone may not be sufficient to predict teachers' willingness to participate in CPD.

Kwakman (2003) examined the factors that affect teachers' participation in professional learning activities. Using the adult learning theory and the social psychological theory of work stress, she found that teachers' participation was influenced mainly by personal factors and workplace factors, which included task and work environment issues. Surveying 542 teachers in 10 secondary schools in the Netherlands, she further suggested that personal factors such as professional attitude and loss of personal accomplishment seemed to have a greater effect than workplace factors on teachers' participation in professional development activities. Considering this finding, it is natural to assume that the factors that affect the application or implementation of the knowledge acquired through professional development activities could also be personal factors.

Teacher participation is the first step in enhancing student learning through CPD, and the second step is the application of CPD knowledge to learning and teaching. A teacher's motivation to engage in CPD might be personal, such as to enrich his or her own knowledge and skills in aspects that could facilitate student learning. However, teachers' personal preferences are usually not the top priority in today's education system. Grundy and Robison (2004) argued that there were two drivers in professional development: systemic provision and personal engagement. Systemic provision emphasises the 'renewal' function, while personal engagement concerns the 'growth' function of CPD. While accountability is commonplace in most school systems, teachers' professional development programmes have become increasingly strategic in promoting a school's image and securing greater managerial control. Hence it is debatable whether the improvement of teacher quality has a positive correlation with participation in CPD programmes (Grundy $\&$ Robison, 2004). The relationship between CPD and student learning is not as direct as one may expect.

\subsection{Teachers' Professional Learning and Small Class Size}

In a study that explored the relationship of teachers' beliefs and pedagogy, Snider and Roehl (2007) found that many teachers strongly believe that small class size is the primary factor for academic success in the primary grades. They revealed that teachers in general expressed strong support for small class teaching or class size reduction, but they also found that teachers tend not to change their teaching practices despite their move from larger to smaller classes (O'Connell \& Smith, 2000). For example, Harfitt (2012) studied teachers' perceptions and practices when teaching in classes of various sizes and showed that even though teachers attempted to individualise their teaching more in small-size classrooms than in larger ones, they did not display a strong pedagogical orientation in favour of a particular class size. This study, together with previous research, revealed that even though teachers prefer small class teaching, many of them do not capitalise on the advantages that a small class size can bring and continue to teach in the same manner as with a large class. One reason that may contribute to this phenomenon is a lack of professional knowledge in reduced-size class teaching (Galton \& Pell, 2009).

Galton, Lai and Chan (2015) maintained that teachers who wish to gain the true benefits of small class teaching must 
understand the theory of small class teaching and acquire the corresponding pedagogical knowledge and skills, such as lesson preparation, questioning techniques, engagement of students' participation, promoting of collaborative learning, assessment design and use of feedback. Each is an important knowledge or skill set that is required to capitalize on small class teaching. While CPD is one means to enhance teaching effectiveness (Harris, 1998), teachers who are new to small class teaching will have to participate in related professional development programmes to take advantage of the reduced class size.

\section{CPD and Student Learning}

Although it is commonly believed that professional development can improve the quality of teaching and learning, studies have shown that many professional development programmes are ineffective and unable to deliver the expected outcomes (Guskey, 2002). What has gone wrong? Educational researchers have attempted to identify the factors that are detrimental to the effectiveness of professional development programmes because the ineffectiveness of a teacher's professional development directly affects student learning (Bredeson, Fruth, \& Kasten, 1983).

According to Avalos (2011), research into the effectiveness of teachers' professional development has two main themes: (1) teacher changes in cognition, beliefs and practices (e.g., Goldschmidt \& Phelps, 2010) and (2) student learning (e.g., Vogt \& Rogalla, 2009). While research in these areas has deepened our understanding of the effects of professional development programmes on teachers' professional growth, the findings have not revealed significant improvements in teacher knowledge. Amongst the three areas of teacher cognition-ideological (norms and values), empirical (connection between phenomena) and technical (methods) (Avalos, 2011, pg. 13)-only improvement in technical knowledge was detected (Ponte, Ax, Beijaard, \& Wubbels, 2004). This means that the effect of CPD initiatives in general is not prominent in enhancing student learning, although there have been individual reported cases of student achievement as a result of the improvement of or changes in teacher practice (Avalos, 2011).

Personal factors are believed to be main reasons for these ineffective professional development programmes (Van Eekelen, Vermunt, \& Boshuizen, 2006). The personal factors that contribute to this ineffectiveness may include teachers' lack of motivation to engage in professional development (Guskey, 1986, 2002), teachers' attitudes toward pedagogical changes (Maskit, 2011), teachers' will to learn (Van Eekelen et al., 2006) and teachers' actual perceptions of professional identity (Beijaard, 1995). This suggests that something must be done regarding these personal factors if teachers' professional development is to be a key component in enhancing teaching and learning in a small class environment.

Avalos (2011) argued that teachers are both subjects and objects of learning and development and that the professional development of teachers is a complex process that requires teachers' cognitive and emotional involvement. As such, most of the works on teacher professional development over the last decade are centred on the teachers' professional growth, even though some of them have downplayed the role of the traditional in-service education and training (INSET) model (Hopkins, 1986). Avalos (2011) also pointed out that the core of professional development endeavours 'is about teachers learning, learning how to learn and transforming their knowledge into practice for the benefit of their students' growth' (p. 10). We may agree that the first two endeavours are important to enhance the quality of teaching; however, it is the last that we most want to achieve. Instead of focusing on the personal factors that may affect the professional growth of the teachers themselves, it is critical to examine the factors that affect the transformation of knowledge into practice that may benefit students. Therefore, a teacher's participation in professional development programmes is only one side of the story; the extent to which teachers can effectively apply the knowledge gained from professional development programmes to their teaching is the other. In reality, enhancing the quality of teaching and learning through professional development programmes has never been direct and simple (Ingvarson, Meiers, \& Beavis, 2005). Many factors affect the application of the pedagogical and content knowledge gained via these programmes.

Scribner (1999) argued that teachers' professional development should be treated as a reform and that professional development initiatives should be integrated into teachers' work and the culture of schools. In other words, professional development is more than a vehicle for reform and should be part of the reform to enrich teachers' learning experiences rather than only meeting passive contractual obligations for professional updating.

Some studies have also indicated that a school's context and structure could determine the effectiveness of its teachers' professional development (Johnson, 1990). Clarke and Hollingsworth (2002) maintained that in contrast to personal factors, the school context can have a significant effect on teachers' professional growth. They argued that such workplace factors can influence four stages of a teacher's professional development process: access to opportunities for professional development, the arrangement of participation, the option to experiment with new teaching techniques and the administrative decisions on the long-term application of new ideas. A teacher's professional growth can be deeply influenced by the school context at every stage of development. The researchers also pointed out that a lack of coordination and leadership, lack of collegiality and the neglect of professional development in some schools adversely affected teachers' motivation or commitment to professional development. 
Identification of the factors that affect teachers' application of the knowledge gained from professional development to their teaching in small class settings could help school administrations to provide appropriate support for teachers and may better enhance the overall effectiveness of the professional development activity. Hence, this study examined teachers' main concerns in applying their knowledge from professional development programmes for small class teaching to their teaching and explored whether personal factors were the predominant factors in the implementation of small class teaching in Hong Kong.

\section{Methods}

\subsection{The Participants}

This study surveyed teachers' perceptions of the factors that affect their adoption of small class teaching after participation in a small class teaching professional development programme. The programme was conducted at a Hong Kong university and commissioned by the Government of HKSAR. The study participants were full-time local primary school teachers who had participated in the programme, including teachers from four key primary subjects: Chinese, English, Mathematics and General Studies. The teachers who had completed the programme $(n=182)$ were invited to complete a questionnaire issued by the instructor at the last meeting of the programme. Finally, 160 valid questionnaires were collected, with a response rate of approximately $88 \%$. The participants remained anonymous to increase the validity of the data.

The self-reporting questionnaire consisted of three main parts. Part 1 consisted of six items designed to gather the teachers' perceptions of their knowledge gained from the small class teaching professional development programme. Part 2 contained one question with 10 options intended to identify the teachers' perceived factors (difficulties) in applying the professional development knowledge to their teaching. Part 3 included three questions to collect information on the participants' teaching experiences and professional backgrounds.

\subsection{The Instrument}

In Part 1 of the questionnaire, the participants were asked to self-evaluate their knowledge gained in six domains of small class teaching: (i) theories of small class teaching, (ii) teaching and learning objectives and lesson preparation, (iii) questioning techniques, (iv) student participation and collaborative learning, (v) assessment design, and (vi) use of feedback. To complete this part, the participants needed to estimate their acquired knowledge in each domain as a percentage by selecting one of four options: $1=0 \%$ to $25 \%, 2=26 \%$ to $50 \%, 3=51 \%$ to $75 \%$ and $4=76 \%$ to $100 \%$. This gave us an indication of the overall effectiveness of the professional development programme in enhancing small class teaching.

In Part 2 of the questionnaire, the participants were asked to identify the perceived factors that affected their use of small class teaching. Table 1 shows the list of perceived factors. The participants were allowed to choose more than one factor. The items were listed randomly and were not labelled on the questionnaire as personal or workplace factors to avoid any interference with their choices.

Table 1. Perceived factors that affect the use of knowledge gained in the SCT professional development programme

\begin{tabular}{ll}
\hline \multicolumn{1}{c}{ Personal factors } & \multicolumn{1}{c}{ Workplace factors } \\
\hline $\begin{array}{l}\text { Scepticism towards the effectiveness of the knowledge } \\
\text { and skills gained }\end{array}$ & $\begin{array}{l}\text { The knowledge gained cannot cater to the school's } \\
\text { particular needs }\end{array}$ \\
$\begin{array}{l}\text { Insufficient knowledge and skills gained } \\
\text { Lack of confidence }\end{array}$ & $\begin{array}{l}\text { Lack of support from colleagues } \\
\text { Cannot find a chance to use the knowledge and skills }\end{array}$ \\
$\begin{array}{l}\text { gained } \\
\text { Other personal factors }\end{array}$ & workload from the seniors \\
\hline
\end{tabular}

Part 3 of the questionnaire, which was optional, gathered information on the participants' years of teaching experience. To facilitate analysis, the years of experience were grouped into 7 categories: 5 years or less, 6 to 10 years, 11 to 15 years, 16 to 20 years, 21 to 25 years, 26 to 30 years and more than 30 years. The participants were also invited to disclose their highest academic qualifications and current position for reference.

\section{Results}

\subsection{Professional Knowledge Gained from Professional Development Programme}

Part 1 of the questionnaire collected the participants' perceptions regarding their knowledge gained from the small class teaching professional development programme. Although this was an anonymous survey, it was evident that some participants found these questions sensitive because only 92 of them completed this part of the questionnaire. The results are shown in Table 2. 
Table 2. Participants' perceived knowledge gained from professional development programme per domain $(\mathrm{n}=92)$

\begin{tabular}{lcc}
\hline \multicolumn{1}{c}{ Domain } & Mean & SD \\
\hline Theories of SCT & 2.87 & .683 \\
Teaching and learning objectives and lesson preparation & 3.11 & .601 \\
Questioning techniques & 3.16 & .700 \\
Student participation and collaborative learning & 3.43 & .634 \\
Assessment design & 2.50 & .703 \\
Use of feedback & 2.88 & .724 \\
\hline
\end{tabular}

Three knowledge domains had mean scores above 3: teaching and learning objectives and lesson preparation, questioning techniques and student participation and collaborative learning, which indicated that the participants believed that they had acquired 51\% to $75 \%$ of the knowledge provided by the professional development programme. For the other three domains - theories of small class teaching, assessment design and use of feedback - the scores ranged from 2.50 to 2.88 , which represented quite low percentages of acquired knowledge. This finding suggests that the participants thought that they only gained $26 \%$ to $50 \%$ of the knowledge in those domains via the small class teaching professional development programme. It seemed that the participants in this study were not very confident in applying these professional development knowledge domains in their teaching. In other words, the participants may not have considered the knowledge gained from the professional development programme as a motivating factor to implement small class teaching. This may be attributed to their inability to integrate theory into practice. The results of this survey indicate that the participants were heavily loaded with teaching duties and administrative responsibilities and, as a result, did not have the chance to try out or experiment with the knowledge they had just gained from the professional development programme. Like other professional development programmes for innovative initiatives, much of the content was new to the participants, and it takes time for them to integrate the knowledge and skills into their daily teaching (Harris and Hofer, 2017). They may have found these programmes to be fraught with confounds if they could not immediately apply what they had acquired in the professional development programme (Wong \& Pow, 2012).

\subsection{Perceived Factors in the Application of Professional Development Knowledge}

The participants' perceived factors in the use of professional development knowledge and skills are shown in Table 3. The data show that insufficient time for preparation due to heavy workload was the most chosen factor $(f=103,64 \%)$, echoing the results of Galton and Pell (2009), who identified major determinants of the capacity to teach effectively in small class teaching in Hong Kong. Amongst the major determinants they reported, the teachers' workload ranked first, followed by better catering for learner diversity, deployment of effective teaching strategies, students' learning capabilities and curriculum adaption (Galton \& Pell, 2009).

Table 3. Participants' perceived factors in the use of professional development knowledge $(n=160)$

\begin{tabular}{lcc}
\hline \multicolumn{1}{c}{$\begin{array}{c}\text { Factors } \\
\text { (In the order they appeared in the questionnaire) }\end{array}$} & $\begin{array}{c}\text { Frequency } \\
\text { (chosen) }\end{array}$ & $\begin{array}{c}\text { Percentage } \\
\text { (chosen) }\end{array}$ \\
\hline The knowledge gained cannot cater to the particular needs of their school & 6 & $3.7 \%$ \\
Scepticism towards the effectiveness of the knowledge and skills gained & 8 & $5 \%$ \\
Insufficient knowledge and skills gained & 18 & $11.2 \%$ \\
Lack of resources and facilities & 30 & $18.6 \%$ \\
Lack of support from the seniors & 14 & $8.7 \%$ \\
Lack of support from colleagues & 25 & $15.5 \%$ \\
Lack of confidence & 9 & $5.6 \%$ \\
Insufficient time for preparation due to heavy workload & 103 & $64 \%$ \\
Cannot find a chance to use the knowledge and skills gained & 4 & $2.5 \%$ \\
Other personal factors & 0 & $0 \%$ \\
\hline
\end{tabular}

The top three perceived factors (difficulties) were insufficient time for preparation due to heavy workload $(f=103,64 \%)$, lack of resources and facilities $(f=30,18.6 \%)$ and lack of support from colleagues $(f=25,15.5 \%)$, all of which were workplace (contextual) factors. With the exception of other personal factors, which no participant had chosen, the bottom three factors were cannot find a chance to use the knowledge and skills gained $(f=4,2.5 \%)$, the knowledge gained cannot cater to the particular needs of their school $(f=6,3.7 \%)$ and scepticism towards the effectiveness of the knowledge and skills gained $(f=8,5 \%)$. Two of these three factors were personal factors. These initial findings indicate that the participants regarded workplace factors as more influential than personal factors in applying small class teaching in Hong Kong primary schools.

Of the 160 participants, 103 identified workload (i.e., insufficient time for preparation due to heavy workload) as the most important factor in their use of small class teaching professional development knowledge in their teaching, even after they participated in the small class teaching professional development programme. Workload greatly outnumbered 
the other factors; the second most chosen factor was selected by only 30 of the 160 participants. To gain a better understanding of the workload, we cross-tabulated this factor against the participants' teaching experience.

Table 4. Cross-tabulation of workload factor against participants' years of teaching experience $(n=160)$

\begin{tabular}{ccccccccc}
\hline Year & $\leq 5$ & $6-10$ & $11-15$ & $16-20$ & $21-25$ & $25-30$ & $>30$ & Total \\
\hline Count & 10 & 26 & 26 & 23 & 12 & 6 & 0 & 103 \\
Participants & 20 & 35 & 45 & 30 & 19 & 11 & 0 & 160 \\
Percentage & $50 \%$ & $74 \%$ & $58 \%$ & $77 \%$ & $63 \%$ & $55 \%$ & $0 \%$ & $64 \%$ \\
\hline
\end{tabular}

Compared to the more experienced participants, those with 5 years of teaching experience or less were less likely to regard workload as an obstacle to their use of professional development knowledge in implementing small class teaching, even though 50\% of them identified workload as a hindrance for their use of small class teaching. Teachers in their first few years of teaching are usually in the induction phase of the Teacher Career Cycle Model (Burke, Christensen, Fessler, Mcdonnell, \& Price, 1987; Fessler, 1992 cited Maskit, 2011). These new teachers are socialised in the school system to gain a sense of security in dealing with daily duties. Hence, they tend not to complain about their heavy workloads and will try to gain acceptance from their colleagues; thus, a relatively lower percentage of these participants chose insufficient time for preparation due to heavy workload.

Most of the participants with 6 to 30 years of experience were senior teachers with administrative duties in addition to their teaching obligations. Thus, they were more concerned with the effects of their workload on the implementation of small class teaching. It is understandable that they regarded workload as one of the factors that prevented them from applying the knowledge of small class teaching gained via professional development to their teaching. The number of participants who felt this way (between 55\% and 77\%) is quite alarming. We are unsure whether this feeling also prevails in other educational initiatives. However, future studies to determine the reasons behind this phenomenon are desirable to gain a better understanding of the effectiveness of professional development programmes in small class teaching.

\section{Discussion}

We studied the factors that affect teachers' use of small class teaching professional development knowledge in Hong Kong. Although the findings are preliminary, we found that the participants regarded workplace factors as more influential than personal factors. We also revealed the participants were lack of enthusiasm for the small class teaching professional development programme. They recounted that the knowledge gained across the six domains was not adequate; they perceived that on average they acquired $51 \%$ to $75 \%$ of the knowledge provided in three of the six domains and only $26 \%$ to $50 \%$ in the remaining three domains. We did not investigate the reasons behind this discrepancy in the participants' perceived knowledge gained and the expected learning outcomes of the small class teaching professional development programme. We therefore cannot, simply attribute the discrepancy to personal factors. Likewise, we cannot eliminate the possibility that workplace factors contributed to this discrepancy.

Choi and Tang (2011) noted that teachers' heavy workloads were a main reason behind for the negative emotions towards and dissatisfaction with the job. In a work-life balance survey conducted in Hong Kong, Chung, Pang, \& Chan (2006) found that only people who worked in education rated their workload as the most important factor contributing to their unhappiness with their job. Their findings showed that $21.3 \%$ rated their workload as the most important factor, while fewer than $10 \%$ of the participants in all other sectors rated it as an important factor. This large difference highlighted that workload is a concern in the field of education in Hong Kong.

We were concerned that the effects could be detrimental if workplace factors such as a heavy workload were the main factors in participation in professional development activities and the application of professional development knowledge. Teachers become frustrated if they could not apply the personal development goals acquired via professional development activities to their teaching, not because they had not paid enough attention to their own professional development but due to workplace factors that were seemingly out of their control. This might explain why many teachers did not significantly alter their practices even though they may have understood the practical benefits of small class teaching (Harfitt, 2012).

Unexpectedly, our data show that the participants were not fully motivated to acquire the small class teaching knowledge available in the professional development programme, as indicated by their self-evaluation results. We did not solicit information regarding their reasons for joining this small class teaching professional development programme, but it could be assumed that if it was for their own professional development in small class teaching, they would be well motivated and score highly across the six knowledge domains. One possible reason for these discouraging results was that the participants who joined the programme did so not for their own development but as part of their duty. They may still have needed to attend to administrative duties in school even though they were released from their daily teaching duties, and as a result they were not able to fully engage in the professional 
development programme. Perhaps their participation was rather passive as per the description by Johnson (1990), in which they are passive members of traditional professional development programmes. Only 20 of the 160 participants in this study had 5 years of teaching experience or less (Table 4). Those with more than 6 years' teaching experience were usually senior teachers and had more administrative duties, which provides side evidence that workload affects willingness to participate in professional development programmes and, hence, the effectiveness of the programme.

One of the merits of small class teaching reform is that teachers can better handle individual differences in the classroom. Teachers can devote more time and effort to the students' individual needs, and student learning is thus expected to be enhanced. Although this small class teaching reform may not call for a change in curriculum, it will inevitably demand a higher performance standard of the teachers, who should demonstrate sound pedagogical knowledge and skills in the implementation of small class teaching. If workplace factors, such as a heavy workload, make the teachers unable to take advantage of small class teaching, they will cause frustration and the students will be less likely to benefit from small class teaching. As highlighted in The Study on Small Class Teaching in Primary Schools in Hong Kong: Final Report by Galton and Pell (2009), 'sharing good practice with colleagues was less valued because any useful knowledge gained could not be put to immediate good use on account of existing workloads' (p. 4).

Given that no additional resources will be provided in the near future, we must identify ways to reduce teachers' workloads so that they can make the best use of the small class environment in their daily teaching. For example, allocating teachers to more than one class in a particular year group would cut down on preparation (Galton \& Pell, 2009). We expect that by reducing teachers' workloads via some innovative endeavours, students in Hong Kong will benefit from small class teaching in the current social and economic situation.

Due to a strong belief that teaching is a solitary activity, team teaching is not prevalent. Hassel and Hassel (2013) wrote that "while others moved toward team-based jobs that let people do what each does best to produce better outcomes together, teaching remained a profession of lonely solo practitioners' (p.3). For school management, the students' academic success or failure is usually on the teachers' shoulders. As such, teachers are reluctant to adopt new approaches to teaching even if they have completed a certain professional development programme on the use of those new approaches. From a socio-cultural perspective (Johnson, Down, Le Cornu, Peters, Sullivan, Pearce, \& Hunter, 2015), this may mean that the effects of workplace factors are greater than those of personal factors in determining change with respect to professional development programmes.

This study shows that workload issues may have greater effects on small class teaching than other professional development initiatives. To successfully implement small class teaching, professional development alone may not be the single most important factor. Even though teachers have the necessary professional knowledge, a bottom-up approach without the support of a school's senior management may not be as effective as expected.

\section{Conclusions}

The problem of workload is not confined to individual teachers; it is a collective issue that every school teacher would need to handle. To do so requires the concerted efforts of the school community (including parents) and continuous support from school management. A bottom-up approach would stand little chance to succeed in tackling the issue of workload. The findings of this study shed light on the reasons that some professional development endeavours do not produce the expected outcomes. Small class teaching would further increase the teachers' workloads and for successful implementation, the teachers' participation in a professional development programme alone would not be a promising approach. It is believed that a team approach that orchestrates the efforts of every teacher in a school is more likely to achieve the goal of successful implementation of small class teaching.

While we should not overlook the importance of personal factors, we should not disregard the effects brought about by workplace factors on the successful application of new professional development knowledge and skills in any educational initiatives. A more balanced view of teachers' professional development is needed to alleviate the pressure on teachers. The professional development activity alone was in itself ineffective; we argue that with a supportive school culture and collective efforts to deal with unforeseeable workplace issues, such as the workload issue identified in this study, successful implementation of small class teaching stands a better chance.

\section{Limitations and Suggestions}

We considered the Teacher Career Cycle Model by Fessler (1992) to be a good analytical framework to classify teachers' rationales for participatation in professional development programmes. The teachers who participated in this study were registered for the professional development programme by their schools, and we were therefore unsure about the factors that affected their participation. While this study only surveyed the participants' perceptions towards their CPD after the programme, no information was gathered about their expectations of and reasons for joining the programme. The research findings would have been more convincing if we had have identified the reasons behind their participation in 
the professional development programme. Hence, further studies should identify both the factors that affect participation and the factors that affect application. Moreover, the study's initial findings are limited to small class teaching professional development. Different factors might affect teachers' use of knowledge from other professional development programmes in their daily teaching.

\section{References}

Advisory Committee on Teacher Education and Qualifications (ACTEQ), (2009). Towards a Learning Profession: Third report on teachers' continuing professional development. Hong Kong Government.

Avalos, B. (2011). Teacher professional development in Teaching and Teacher Education over ten years. Teaching and Teacher Education, 27(1), 10-20. https://doi.org/10.1016/j.tate.2010.08.007

Beijaard, D. (1995). Teachers' prior experiences and actual perceptions of professional identity. Teachers and Teaching: Theory and Practice, 1, 281-294. https://doi.org/10.1080/1354060950010209

Blatchford, P., Bassett, P., Goldstein, H., \& Martin, C. (2003). Are class size differences related to pupils' educational progress and classroom processes? Findings from the Institute of Education Class Size Study of Children Aged 5-7 Years. British Educational Research Journal, 29(5), 709-730. https://doi.org/10.1080/0141192032000133668

Bredeson, P. V., Fruth, M. J., \& Kasten, K. (1983). Organizational incentives and secondary school teaching. Journal of Research and Development in Education, 16(4), 52-58.

Burke, P. J., Christensen, J. C., Fessler, R., McDonnell, J. H., \& Price, J. R. (1987). April. The teacher career cycle: Model development and research report. Paper presented at the annual meeting of the American Educational Research Association, Washington.

Çakmak, M. (2009). The perceptions of student teachers about the effects of class size with regard to effective teaching process. The Qualitative Report, 14(3), 395-408. http://nsuworks.nova.edu/tqr/vol14/iss3/2

Choi, P. L., \& Tang, S. Y. F. (2011). Satisfied and dissatisfied commitment: Teachers in three generations. Australasia Journal of Teacher Education, 36(7), 45-75. https://doi.org/10.14221/ajte.2011v36n7.6

Chung, R. T. Y., Pang, K. K. L., \& Chan, K. S. L. (2006). Work Life Balance Survey of the Hong Kong Working Population 2006. Available from http://hkupop.hku.hk/chinese/report/wlb06/report.pdf [Accessed 17 April 2014]

Clarke, D., \& Hollingsworth, H. (2002). Elaborating a model of teacher professional growth. Teaching and Teacher Education, 18(8), 947-967. https://doi.org/10.1016/S0742-051X(02)00053-7

Edmonds, C. (2007). Continuous quality improvement: Integrating best practice into teacher education. International Journal of Educational Management, 21(3), 232-237. https://doi.org/10.1108/09513540710738674

Fessler, R. (1992). The teacher career cycle. In: R. Fessler and J.C. Christensen, Eds. The teacher career cycle. Boston: Allyn and Bacon, 21-44.

Fessler, R., \& Christensen, J. C. (1992). Summary and synthesis of career cycle model. In: R. Fessler and J. C. Christensen, Eds. The teacher career cycle. Boston: Allyn and Bacon, 249-268.

Finn, J. D., Pannozzo, G. M., \& Achilles, C. M. (2003). The "why's" of class size: Student behavior in small classes. Review of Educational Research, 73(3), 321-368. https://doi.org/10.3102/00346543073003321

Galton, M., \& Pell, T. (2009). Study on small class teaching in primary schools in Hong Kong: Final report. Education Bureau, the Government of the Hong Kong Special Administrative Region of the People's Republic of China.

Galton, M., Lai, K. C., \& Chan, K. M. (2015). Learning to teach small classes: Lessons from East Asia. London: Routledge.

Goldschmidt, P., \& Phelps, G. (2010). Does teacher professional development affect content and pedagogical knowledge: How much and for how long? Economics of Education Review, 29(3), 432-439. https://doi.org/10.1016/j.econedurev.2009.10.002

Graue, E., Hatch, K., Rao, K., \& Oen, D. (2007). The wisdom of class-size reduction. American Educational Research Journal, 44(3), 670-700. https://doi.org/10.3102/0002831207306755

Grundy, S., \& Robison, J. (2004). Teacher professional development: Themes and trends in the recent Australian experience. In: C. Day and J. Sachs, Eds. International handbook on the continuing professional development of teachers, London: McGraw-Hill, 146-166.

Guskey, T. R. (1986). Staff development and the process of teacher change. Educational Researcher, 15(5), 5-12. https://doi.org/10.3102/0013189X015005005 
Guskey, T. R. (2002). Professional development and teacher change. Teachers and Teaching: Theory and Practice, 8(3), 381-391. https://doi.org/10.1080/135406002100000512

Harfitt, G. J. (2012). An examination of teachers' perceptions and practice when teaching large and reduced-size classes: Do teachers really teach them in the same way? Teaching and Teacher Education, 28(1), 132-140. https://doi.org/10.1016/j.tate.2011.09.001

Harris, A. (1998). Effective teaching: A review of the literature. School Leadership and Management, 18(2), 167-183. https://doi.org/10.1080/13632439869628

Harris, J. B., \& Hofer, M. J. (2017). “TPACK Stories”: Schools and school districts repurposing a theoretical construct for technology-related professional development. Journal of Research on Technology in Education, 49(1-2). Advance online publication. https://doi.org/10.1080/15391523.2017.1295408

Hassel, E. A., \& Hassel, B. C. (2013). An opportunity culture "for all": Making teaching a highly paid, high-impact profession. Public Impact. Available from http://opportunityculture.org/wp-content/uploads/2013/09/An_Opportunity_Culture_for_All-Public_Impact.pdf [Accessed 4 August 2014]

Hopkins, D., ed., (1986). In-service training and educational development: An international survey. London: Croom Helm.

Ingvarson, L., Meiers, M., \& Beavis, A. (2005). Factors affecting the impact of professional development programs on teachers' knowledge, practice, student outcomes and efficacy. Education Policy Analysis Archives, 13(10). https://doi.org/10.14507/epaa.v13n10.2005

Johnson, B., Down, B., Le Cornu, R., Peters, J., Sullivan, A., Pearce, J., \& Hunter, J. (2015). Promoting early career teacher resilience: A socio-cultural and critical guide to action. London: Routledge.

Johnson, S. M. (1990). Teachers at work: Achieving success in our schools. New York: Basic Books.

Kwakman, K. (2003). Factors affecting teachers' participation in professional learning activities. Teaching and Teacher Education, 19(2), 149-170. https://doi.org/10.1016/S0742-051X(02)00101-4

Maskit, D. (2011). Teachers' attitudes toward pedagogical changes during various stages of professional development. Teaching and Teacher Education, 27(5), 851-860. https://doi.org/10.1016/j.tate.2011.01.009

O’Connell, J., \& Smith, S. C. (2000). Capitalizing on Small Class Size. ERIC Digests Number 136, 2002-2003. http://hdl.handle.net/1794/3359

Pedder, D. (2006). Are small classes better? Understanding relationships between class size, classroom processes and pupils' learning. Oxford Review of Education, 32(2), 213-234. https://doi.org/10.1080/03054980600645396

Ponte, P., Ax, J., Beijaard, D., \& Wubbels, T. (2004). Teachers' development of professional knowledge through action research and the facilitation of this by teacher educators. Teaching and Teacher Education, 20(6), 571-588. https://doi.org/10.1016/j.tate.2004.06.003

Scribner, J. P. (1999). Professional development: Untangling the influence of work context on teacher learning. Educational Administration Quarterly, 35(2), 238-266. https://doi.org/10.1177/0013161X99352004

Snider, V. E., \& Roehl, R. (2007). Teachers' beliefs about pedagogy and related issues. Psychology in the Schools, 44(8), 873-886. https://doi.org/10.1002/pits.20272

Van Eekelen, I. M., Vermunt, J. D., \& Boshuizen, H. P. A. (2006). Exploring teachers' will to learn. Teaching and Teacher Education, 22(4), 408-423. https://doi.org/10.1016/j.tate.2005.12.001

Vogt, F., \& Rogalla, M. (2009). Developing adaptive teaching competency through coaching. Teaching and Teacher Education, 25 (8), 1051-1060. https://doi.org/10.1016/j.tate.2009.04.002

Wong, M., \& Pow, J. (2012). Initiating small class teaching in Hong Kong: Video reflective narratives and the professional developmental learning model. Teacher Development, 16(4), 507-522.

https://doi.org/10.1080/13664530.2012.730713

\section{Copyrights}

Copyright for this article is retained by the author(s), with first publication rights granted to the journal.

This is an open-access article distributed under the terms and conditions of the Creative Commons Attribution license which permits unrestricted use, distribution, and reproduction in any medium, provided the original work is properly cited. 